\title{
Hesio Cordeiro e a construção do Sistema Único de Saúde
}

| ${ }^{1}$ José Carvalho de Noronha |

1 Instituto de Medicina Social Hesio Cordeiro, Universidade do Estado do Rio de Janeiro. Rio de Janeiro-RJ, Brasil (noronhajc@gmail.com).
ORCID: 0000-0003-0895-6245
Recebido em: 02/06/2021
Aprovado em: 03/08/2021
Revisado em: 23/08/2021
DOI: http://dx.doi.org/10.1590/S0103-73312021310306

Mas uma coisa é proclamar esse direito, outra é desfrutá-lo efetivamente. A linguagem dos direitos tem indubitavelmente uma grande função prática, que é emprestar uma força particular às reivindicaçóes dos movimentos que demandam para si e para os outros a satisfação de novos carecimentos materiais e morais; mas ela se torna enganadora se obscurecer ou ocultar a diferença entre o direito reivindicado e o direito reconhecido e protegido. Norberto Bobbio

\section{Prólogo}

Hesio Cordeiro foi uma personagem absolutamente central para a construção dos pilares nos quais se assenta o SUS, o denominado Sistema Único de Saúde. Por sua inteligência, sua formação, ousadia, capacidade de argumentação, energia, gentil teimosia, capacidade de negociação e de construção institucional. E, mais, pela capacidade de identificar corretamente os agentes políticos capazes de mover o processo que culminou nos dispositivos sobre a Seguridade Social e, nela, sobre a Saúde, na Constituição de 1988. 
Reinaldo Guimarães e Ricardo Tavares, na apresentação do livro que organizaram, Saúde e Sociedade nos anos 80, recordam o clima em que as ideias que preenchiam os jovens médicos que adentravam o terreno da então chamada Medicina Social na década de 1970. Resistia-se à Ditadura, mas se começava a pensar em alternativas.

[...] naquele tempo havia a Utopia, onde costumávamos nos mover embalados pelas determinações de uma das três Internacionais Socialistas, de acordo com o gosto de cada freguês. Feldshers soviéticos, médicos de pés-descalços chineses, policlínicas cubanas. $\mathrm{O}$ National Health Service britânico e alguma característica do sistema de saúde sueco, de que já não lembramos, modelavam nosso sonhos político-sanitários recheados de equidade e justiça social”.

O Instituto de Medicina Social, sob a liderança de Hesio e Nina Pereira Nunes, abrigava parte importante dessa turma. Daí a primeira "compilação" de teses feita por ele Reinaldo, José Luís Fiori, que resultou no documento do Centro Brasileiro de Estudos de Saúde (Cebes), "A questão democrática na área da Saúde”, que ganharia status de diretrizes políticas ao ser apresentado por Sérgio Arouca e incorporado aos anais do I Simpósio sobre Política Nacional de Saúde da Câmara dos Deputados em 1979.

Ali estão as diretrizes conceituais e estratégicas para a reorganização radical da sociedade brasileira e de seu sistema de saúde em particular. Depois de breves considerações sobre a degradação das condiçôes de vida e saúde da população em decorrência de uma sociedade assentada em um modelo socioeconômico concentrador e excludente da grande maioria da população, são especificadas as teses centrais para a reorganização setorial.

Parte da afirmação da Saúde como direito universal e inalienável, comum a todos os homens, dos condicionantes socioeconômicos sobre a saúde das pessoas, da importância do acesso aos cuidados de saúde como parte desses direitos, e da responsabilidade do Estado e da sociedade para a garantia desse direito. Em proposiçōes mais específicas, discorre sobre a necessidade de obstaculizar os mecanismos de mercado que favorecem o empresariamento predatório; de se proceder à criação de um Sistema Único de Saúde; de que se garantam mecanismos de financiamento adequado do sistema que não representem gravames adicionais sobre a maioria da população; que se promova uma descentralização articulada que integre as açôes da União, estados e municípios. 


\section{Primeiros caminhos}

Hesio, na segunda metade da década de 1970, já tem sua liderança afirmada no campo acadêmico no campo da Medicina Social/Saúde Coletiva. Ocorre que não lhe era estranho o ativismo político energizado pela sua capacidade articuladora e por sua criatividade nas iniciativas de construção institucional. Naquele período, o Brasil começava a emergir de um dos períodos mais duros do regime em direção à denominada "distensão lenta, gradual e segura" do Governo Geisel, subsequente à derrota eleitoral em 1974, quando o MDB elegeu 16 das 22 vagas em disputa para o Senado Federal e quase atinge a maioria na Câmara. Tem início uma expansão e rearticulação do movimento sindical e de outros movimentos populares, e, em 1979, é promulgada a Lei da Anistia. Há intensa rearticulação de intelectuais progressistas tanto em associaçóes ou centros de pesquisa quanto no interior do próprio MDB.

Nas eleiçôes municipais de 1976, algumas prefeituras são conquistadas por segmentos mais à esquerda do $\mathrm{MDB}$, como Campinas, Londrina e Niterói, que começam a implementar políticas inovadoras de expansão de cobertura e reorganização dos cuidados de saúde, inspiradas naqueles modelos e, muitas delas, derivadas de "experimentos" universitários precedentes, como os do próprio Instituto de Medicina Social da UERJ, em Austin, no Município de Nova Iguaçu. Hesio acompanha esses primórdios do que será chamado de movimento da Reforma Sanitária Brasileira.

De particular e profícua inspiração para o entendimento e intervenção nas políticas de saúde foram suas interaçóes com Carlos Gentile de Mello, Nildo Aguiar e Murilo Vilela Bastos. Na realidade, já nas discussōes que se mantêm no interior da Previdência Social, que resultaram na Lei n. 6.229/1975, dispondo sobre a organização do Sistema Nacional de Saúde, e que representou o primeiro esforço de integração e articulação nacional no âmbito da União, estados e municípios, podem ser encontradas digitais de Hesio.

\section{A virada dos anos 1980}

Um marco importante na evolução do sistema de saúde nesse sentido, apontado acima, se deu no interior do INAMPS (Instituto Nacional de Assistência Médica da Previdência Social, subordinado ao Ministério da Previdência Socia), sob a Presidência de Aloysio de Salles Fonseca, que desenvolveu o chamado Plano do 
CONASP (Conselho Consultivo de Administração de Saúde Previdenciária) em 1982. Foram então estabelecidas estruturas nacionais, estaduais, microrregionais e municipais de integração entre os gestores das respectivas esferas de governo e, sobretudo, de apoio financeiro a prestadores públicos e privados, preferencialmente filantrópicos, para atendimento à população em geral, sem necessidade de comprovação de filiação contributiva à Previdência, as chamadas "Açôes Integradas de Saúde" (ver, por exemplo, PAIM, 1986).

Do ponto de vista político, no sentido da derrota da ditadura, foram as eleiçôes gerais e diretas para os governos estaduais de 1982. Não apenas os partidos oposicionistas obtiveram maioria na Câmara Federal, como elegeram 11 dos 22 governos em disputa e, entre eles, governadores com perfil de centro-esquerda São Paulo, Paraná, Rio de Janeiro e Espírito Santo.

Outro marco importante foram suas contribuições no campo da saúde, que abasteceram o documento "Esperança e Mudança”, lançado em 1982, considerado o último grande marco do nacional-desenvolvimento, com forte componente na área social, junto com outros sanitaristas e economistas que consolidam a aproximaçáo de Hesio com o PMDB. Da mesma forma, participava ativamente do Diretório da 17a Zona Eleitoral do Rio e contribuiu, com vários companheiros, para a elaboração do Programa de Governo do Partido para as eleiçóes estaduais daquele ano. Participou no movimento pela Anistia e pelas Eleiçóes Diretas.

Em 1983, Hesio assumiu a Presidência da Abrasco (Associação Brasileira de Saúde Coletiva), já engajada em um amplo processo de luta pela construçáo de um Brasil mais democrático, justo e soberano, por reformas do sistema de saúde brasileiro e na difusão do pensamento crítico sobre as relaçôes saúde e doença. Nessa condição, adquiriu um protagonismo decisivo na área da Saúde no processo da transição democrática.

\section{A Nova República}

Com a formação da Aliança Democrática e a eleição indireta de Tancredo Neves, o chamado "grupo autêntico", liderado por Ulysses Guimarães, se faria representar na Nova República, na área social, no Trabalho e na Previdência Social, e na Ciência e Tecnologia, com Renato Archer. A Previdência foi ocupada por Waldir Pires, que, depois de grande mobilização em torno do nome de Hesio, o conduziu à 
Presidência do INAMPS. No mesmo Gabinete, o Ministério da Saúde foi entregue a um parlamentar do "Centrão" de então, Carlos Santana, que, no entanto, nomeou dois quadros importantes da esquerda do movimento sanitário: Eleutério Rodrigues Neto, para a Secretaria Geral do Ministério, e Sérgio Arouca, para a Presidência da Fundação Oswaldo Cruz.

Waldir Pires convocou para a Secretaria de Serviços Médicos, José Saraiva Felipe, que integrava o "grupo de Montes Claros, MG", da mesma extração política de Hesio. Para compor sua equipe na direção nacional, Hesio foi buscar a contribuição dos que haviam trabalhado na elaboração do Plano do CONASP, quadros técnicos progressistas do próprio INAMPS, como Afonso Vigário de Moura e Telma Ruth Pereira, em companheiros da luta do Cebes e da Abrasco, e lideranças de algumas iniciativas progressistas municipais. Destacam-se Henri Jouval Jr., que liderara o grupo que elaborou o Plano do CONASP e ocuparia a Secretaria de Medicina Social da autarquia, o autor destas linhas, que o acompanhava desde 1973 no IMS e trazia a experiência de implantação das AIS no Rio de Janeiro, com Nildo Aguiar e Maria Manuela dos Santos (que havia participado do Projeto Niterói junto com a Prefeitura Municipal, à época ocupada por Moreira Franco, ainda no grupo à esquerda do MDB), seria seu Chefe de Gabinete e sucederia Jouval na SMS, José Gomes Temporão, ex-Presidente do Cebes, seria seu Secretário de Planejamento. Do IMS, ainda integrou a Direção Geral, Eduardo Levcovitz.

Nos estados e seus órgãos microrregionais, foi efetuada uma composição política adernada ao grupo autêntico do PMDB, mas com integrantes de outros segmentos do PMDB e do Partido da Frente Liberal (PFL) que integrava a Aliança Democrática.

Dada a força política e financeira do INAMPS frente ao Ministério da Saúde, caberia a Hesio liderar os principais movimentos em direção à integração das ações de saúde no âmbito federal, estadual e municipal e ao pretendido processo de descentralização e desconcentração das açôes da União para os entes subnacionais. Ademais, para o avanço de uma agenda progressista, as articulaçóes com o grupo autêntico do PMDB que mantinha e cultivava foram extremamente importantes, sobretudo depois do processo das eleições da Assembleia Nacional Constituinte e Governos Estaduais de 1986.

O Ministério da Saúde - com a exceção do Instituto Nacional do Câncer, do Hospital de Curicica, dos três hospitais psiquiátricos, todos no Rio de Janeiro, e da Fundação SESP, com presença nas Regióes Norte, Nordeste e Minas Gerais - 
praticamente não exercia funções assistenciais. Sua função centrava-se na coordenação do Programa Nacional de Imunizaçóes, no combate a endemias como malária, esquistossomose e doença de Chagas e açôes normativas para controle de tuberculose, hanseníase e outras poucas. Tinha também açôes de coordenação do sistema nacional de vigilância sanitária e mantinha a Fundação Oswaldo Cruz, no Rio de Janeiro, e o Instituto Evandro Chagas, no Pará.

O Brasil, por volta de 1985, contava com pouco mais de 130 milhóes de habitantes, com cerca de 73 por cento vivendo em cidades. A mortalidade infantil ainda era extremamente elevada para um país de renda média (63 óbitos por mil nascidos vivos) e a esperança de vida ao nascer não atingia os 70 anos, refletindo a extrema iniquidade distributiva de renda e acesso a serviços essenciais, entre os quais os de saúde.

\section{As mudanças}

É importante recordar que, naquela altura, o acesso aos cuidados de saúde ainda se encontrava segmentado e fragmentado. Os serviços próprios do INAMPS só eram acessíveis aos detentores de contratos formais de trabalho e, a despeito do Funrural, o acesso da populaçáo do campo era restrito pelo modelo e montante do financiamento. Apenas 21 por cento da populaçáo era coberta pela Previdência Social. O "proletariado moderno", em sua imensa maioria em São Paulo, era atendido pelas "empresas médicas", planos de saúde privados. O resto da população, denominada de "indigente", recorria às Santas Casas (que atravessavam grave crise financeira) e aos serviços gratuitos prestados por estados e municípios ("Açóes Integradas de Saúde” encontravam-se restritas a menos de 250 municípios).

Nas próprias palavras de Hesio

A estratégia de mudança deveria se manifestar desde as primeiras medidas administrativas da nova gestáo.... A universalização do acesso, a integralidade das açôes para superar a clássica dicotomia prevenção vs cura e unificação dos serviços através das AIS seriam os vetores da ação estratégica.

Algumas medidas no sentido da universalização do acesso, entretanto, já podiam ser implementadas por iniciativa direta e própria do INAMPS. Já nos primeiros meses, foi abolida a necessidade de demonstração de vínculo contributivo com a Previdência para acesso à rede própria de serviços que, à época, contava com 614 postos de assistência médica e 41 hospitais em diversos pontos do país. Igualmente, 
procedeu-se ao pagamento dos atendimentos prestados pelas Santas Casas e demais entidades filantrópicas aos "indigentes", e alteraram-se os mecanismos de pagamento às unidades que prestavam serviços ao Funrural, permitindo que ampliassem seus atendimentos à população rural.

Para a ampliação da cobertura, ainda se fazia necessário aumentar a base de prestadores, tanto quantitativa como territorialmente. A expansão das AIS poderia assegurar esse processo, ademais de obrigar uma integraçáo, tanto do ponto de vista das açóes preventivas e curativas, quanto das esferas governamentais, e descentralização efetiva de serviços. Já no final de 1985, 644 municípios teriam assinado termos de adesão, atingindo quase 2.500 ao final de 1986, com todos do Rio de Janeiro e Paraná, e mais de 80 por cento em Minas Gerais, Pernambuco, Piauí, Rio Grande do Sul e São Paulo. Registre-se que nesse período ainda não haviam ocorrido as eleiçóes gerais de 1986, quando o PMDB elegeu 22 dos 23 governos estaduais em disputa, grande parte deles com inclinação à esquerda no espectro político. A capacidade de negociação e firmeza de Hesio são ingredientes fundamentais para o sucesso dessa agenda reformista.

Mas a agenda de Hesio ainda abrigava outros componentes. A renovação do pensamento e da formação no campo da Saúde Pública, primeiramente denominada de Medicina Social e, em seguida, Saúde Coletiva, que havia liderado, junto com Sebastiáo Loureiro, da Universidade Federal da Bahia e Guilherme Rodrigues da Silva e Cecília Donnangelo, da Universidade de São Paulo, sob a inspiração de Juan Cesar Garcia, a partir da Organização Panamericana de Saúde, na primeira metade da década de 1970, seria estimulada pelo INAMPS. Sob a coordenação de José Paranaguá de Santana, igualmente originário do movimento da reforma sanitária, foram desencadeadas, simultaneamente, três linhas de atuação: a criação de Núcleos de Saúde Pública/Saúde Coletiva, reunindo instituiçôes acadêmicas e Secretarias de Saúde, destinados a desenvolver pesquisas e educação permanente no âmbito dos próprios serviços de saúde (dez núcleos com essa finalidade foram implantados); o fortalecimento e ampliação da rede das escolas técnicas para formação de pessoal de nível médio (Projeto Larga Escala); e incentivos para projetos de integração ensinoserviços na graduação das carreiras da saúde.

Igualmente, outro componente de suas investigaçóes na segunda metade dos anos 1970, quando explorou a "indústria da saúde" e o que viria a ser denominado complexo econômico-industrial da saúde, criou, no âmbito da Direção Nacional, 
uma Coordenação de Ciência e Tecnologia, que seria liderada por Ana Tereza Pereira, com o triplo propósito de apoiar pesquisas sobre saúde e sistemas de saúde, estabelecer mecanismos internos de gestão de equipamentos e trazer os primeiros elementos de avaliação tecnológica que haviam se iniciado pelo Escritório da Avaliação Tecnológica do Congresso dos Estados Unidos, sob a coordenação de David Banta.

Para a agenda de pesquisa em saúde e suporte a programas de pós-graduação, mobilizou recursos em conjunto com a FINEP (Financiadora de Estudos e Projetos), subordinada ao Ministério da Ciência e Tecnologia, sob a Presidência de Fabio Celso Macedo Soares, através da Diretoria comandada por Reinaldo Guimarães, para apoiar e desenvolver programas que seriam desenvolvidos por várias Universidades e Centros de Pesquisa brasileiros.

Não lhe escapavam as preocupaçôes com a saúde do Trabalhador, quando apoiou a criação e o desenvolvimento de um Centro de Pesquisa e Ensino na Fundação Oswaldo Cruz, com Ana Maria Tambellini à sua frente. Criou ainda, junto à Presidência, uma assessoria para estimular a participação comunitária, a cargo de Lúcia Souto e Anna Maria Noronha, e uma comissão especial para tratar da incorporação de práticas alternativas entre os serviços apoiados pelo INAMPS. Em relação a este último, foram criados ambulatórios de homeopatia em um hospital em Nova Iguaçu e em um posto no Centro do Rio de Janeiro.

\section{Rearranjos políticos institucionais}

Apesar da existência de um razoável consenso quanto à política das Açôes Integradas de Saúde e da importância do comando único para a gestão do sistema de saúde a cada nível de governo, sua implementação, inaugurada a Nova República, padecia de acordos e mecanismos de natureza política e administrativa. A começar no nível federal, onde rapidamente se estabeleceu uma disputa entre os Ministérios da Saúde e da Previdência. Carlos Santana e Waldir Pires eram baianos do PMDB. Um do centro (já chamado de "Centrão"), o segundo do grupo "autêntico". Nominalmente, não seria de todo estranho que o INAMPS passasse a se subordinar ao Ministério da Saúde, posição que aliava o político centrista com seu Secretário Geral, do movimento sanitário de esquerda. Entretanto, o poder e a capacidade de implementação de políticas reais, não discursivas, do INAMPS, era mais de dez vezes superior ao do MS, como ficou logo evidente pelas primeiras medidas 
tomadas por Waldir e Hesio. Do ponto de vista gerencial, o MPAS dispunha de estrutura arrecadatória própria, que facilitava o financiamento de suas açôes diretas, conveniadas e contratadas. Não fazia sentido romper essa proximidade. Do ponto de vista político, o governo era de coalizão. Seria absurdo passar a segmentos mais conservadores tal máquina administrativa.

Nas Unidades Federadas, e também nos órgãos locais, a situação era mais grave. Em todos, a presença do INAMPS era superior à das próprias Secretarias Estaduais de Saúde e, exceto onde a Fundação SESP, ações de controle de endemias eram desenvolvidas e no Rio de Janeiro, a presença do MS era insignificante. A potência das Superintendências Regionais e Órgãos Locais (microrregionais) do INAMPS os tornava alvos de ambição política por lideranças que compunham a Aliança Democrática que elegeu Tancredo Neves e que mais frequente do que excepcionalmente, disputavam com o grupo dos "autênticos" e com outros alinhamentos nos estados e municípios.

De qualquer forma, formou-se uma aliança no MS entre o grupo do ministro e parte do movimento sanitário. Este foi buscar a mobilização de bases populares, sob o manto do controle social e da gestão participativa, para que além da transferência do INAMPS para o Ministério da Saúde, se associasse uma agenda mais ampla para fixar a Saúde como Direito, uma reorganização setorial mais ampla e a definição clara de mecanismos que ampliassem e tornassem mais justo o financiamento do setor. Com essa agenda, o Presidente Sarney convocou, "sob os auspícios do Ministério da Saúde”, em julho de 1985, a $8^{a}$ Conferência Nacional de Saúde (Decreto-Lei n. 91.466, de 23/07/1985), que se realizou em março de 1986 sob a Presidência de Sérgio Arouca, então Presidente da Fundação Oswaldo Cruz.

Para transitar das resoluçóes contidas no relatório da Conferência para a construção de uma agenda concreta de definição da política nacional de saúde, e já tomando em conta os trabalhos da Assembleia Nacional Constituinte, foi constituída, por Portaria Interministerial (Saúde, Previdência e Educação), a Comissão Nacional da Reforma Sanitária, presidida por Arlindo Fábio Gomez de Souza.

Em fevereiro de 1986, Waldir Pires se afastou para disputar o Governo da Bahia, sendo substituído por Raphael de Almeida Magalhães, também integrante do grupo ulyssista do PMDB; e Carlos Santana, por Roberto Santos, baiano e de um grupo independente do PMDB. 


\section{A Constituinte}

Em novembro de 1986, quase 70 milhóes de eleitores, pouco mais da metade da população brasileira, e já incluindo os analfabetos, foram às urnas para escolher os governadores estaduais e eleger um Congresso que teria poderes de uma Assembleia Nacional Constituinte unicameral. Era o apogeu do Plano Cruzado. O PMDB elegeu 22 dos 23 governos em disputa e a maioria da Câmara e do Senado.

Essa conjuntura fortaleceu o Ministro Raphael e sua equipe, que teria grande papel junto aos constituintes e refrearia os movimentos de transferência do INAMPS para o Ministério da Saúde através fundamentalmente de dois movimentos: na Constituinte, articulando um Capítulo dedicado à Seguridade Social, definida como conjunto integrado de ações de saúde, previdência e assistência social, incluindo definições de contribuiçóes específicas para seu financiamento; e por outro, radicalizando as AIS através da implantação dos SUDS, Sistemas Unificados e Descentralizados de Saúde (Decreto n. 94.567, de 20/07/1987), descentralizando para os entes subnacionais as tarefas de coordenação das ações de saúde, ao ponto de promover a nomeação para Superintendentes Regionais, os respectivos Secretários Estaduais de Saúde. Para ambos, o protagonismo de Hesio foi absolutamente crítico. Sobretudo para quebrar a resistência de segmentos do movimento da reforma sanitária que insistiam na separação radical, inclusive na Constituição, da Saúde da Seguridade, inclusive renunciando a mecanismos solidários de financiamento e jogando-o na disputa tributária geral.

Junto à Constituinte, a habilidade e a firmeza de Hesio, construindo apoios junto a governadores e aos parlamentares mais identificados com valores democráticos e de justiça social, facilitaram a inscrição do Capítulo da Seguridade e a inclusão na Seção sobre a Saúde de grande parte das teses que vinham sendo construídas desde o documento do Cebes dos anos 1970. De fundamental importância foram os relatores da Comissão da Ordem Social, Almir Gabriel, e da Subcomissão de Saúde, Seguridade e do Meio Ambiente, Carlos Mosconi, ambos no PMDB à época. Para a formação de consensos técnicos políticos, companheiros da reforma sanitária tiveram papel destacado, entre os quais, Sérgio Arouca, Nelson Rodrigues dos Santos, Arlindo Fábio Gomez de Souza, Eleutério Rodrigues Neto e Moises Goldbaum.

Em janeiro de 1988, encontrava-se concluído o chamado "Projeto A" da Constituição, com uma proposta de alteração relevante apresentada pelo "Centráo" 
quanto à participação da iniciativa privada no sistema de saúde brasileiro, cancelando restriçóes impostas pela versão saída da Comissão da Ordem Social. No resto, sofreria poucas alteraçôes, confirmando as bases constitucionais para construção do Sistema Único de Saúde.

A Constituinte, em suas disposiçóes políticas, vinha sendo tensionada por disputas quanto à mudança para o regime parlamentarista e a duração do mandato presidencial, se de 4 ou 5 anos. Com o fracasso dos Planos Cruzados, o Presidente Sarney rearticulou em torno do Centrão e do PFL sua base congressual e iniciou um grande processo de minimizar o protagonismo dos governadores do PMDB e de Ulysses Guimarães. Em março de 1988, foi aprovada a manutenção do regime presidencialista, e em junho, o mandato de 5 anos. Do grupo ulyssista, Raphael e o autor deste artigo iriam ocupar as Secretarias de Cultura e Saúde do Governo Moreira Franco, naquela altura ainda alinhado com o grupo mais progressista do PMDB. Essa rearticulaçáo parlamentar conduziria ao afastamento de Hesio da Presidência do INAMPS e sua substituição pelo médico particular de Sarney, José Serrão, ainda que o Ministério tivesse passado para Renato Archer, onde ficou por pouco tempo, sendo substituído por Jader Barbalho. Embora Jader fosse um conciliador no interior do PMDB, como o novo Ministro da Saúde, Borges da Silveira, Sarney, que já tinha o INAMPS sob seu controle pessoal, nomeou Seigo Suzuki, médico do Instituto do Coração da Universidade de São Paulo, em substituição a Borges, e imediatamente fez a transferência do INAMPS para o Ministério da Saúde, interrompendo drasticamente os processos do SUDS e adotando uma política de tratamento direto com os municípios.

Afortunadamente, as marcas de atuação de Hesio já estavam solidamente inscritas na Constituição Cidadã de 1988. Serviram de alicerce para a construçáo e avanços do SUS. E também como ponto de resistência aos ataques que se sucederam desde então.

\section{Referências}

BOBBIO, N. A era dos direitos. Rio de Janeiro: Elsevier, 2004; 7a reimp. p.11.

CÂMARA DOS DEPUTADOS. Portal da Constituição Cidadã. Disponível em https:// www2.camara.leg.br/atividade-legislativa/legislacao/Constituicoes_Brasileiras/constituicaocidada/o-processo-constituinte/o-processo-constituinte. Acesso em: 22 maio 2021. 
CENTRO BRASILEIRO DE ESTUDOS DE SAÚDE. A questão democrática na área da Saúde. Saúde em Debate, v. 9, p. 11-13, 1980.

CORDEIRO, H. A indústria da saúde no Brasil. Rio de Janeiro: Ediçôes Graal, 1980.

CORDEIRO, H. As empresas médicas- as transformaçóes capitalistas da prática médica. Rio de Janeiro: Graal, 1984.

CORDEIRO, H. Sistema único de saúde. Rio de Janeiro: Ayuri Editorial, 1991.

ESCOREL, S. História das políticas de saúde no Brasil de 1964 a 1990: do golpe militar à reforma sanitária. In: GIOVANELLA, L. et al. (Orgs.). Políticas e sistema de saúde no Brasil. 2. Ed. Rio de Janeiro: Editora Fiocruz, 2012. p. 323-363.

NORONHA, J. C.; LEVCOVITZ, E. AIS-SUDS-SUS: os caminhos do direito à saúde. In: GUIMARÃES, R.; TAVARES, R. (Orgs.). Saúde e sociedade no Brasil: anos 80. Rio de Janeiro: Relume Dumará, 1994. p. 73-111.

PAIM, J. S. Ações integradas de saúde (AIS): por que não dois passos atrás. Cad. Saúde Pública. Rio de Janeiro, n. 2, p. 167-183, 1986. 